\title{
Mindfulness y la intersubjetividad normada como dos productos disímile. del pensamiento autopoiético
}

\author{
Mariano Esteban Saulig \\ mail: saulig.mariano@gmail.com
}

\section{Resumen}

Se analizarán comparativamente los planteos y bases filosóficas de Samaja y Varela, Thompson y Rosch con el objetivo de señalar los diversos caminos de reflexión que ambas perspectivas delineana pesar de tener una base común en el pensamiento autopoiético desarrollado por Maturanay Varela. En esta dirección, el autor argentino se centra en la importancia de la subjetividad normada en tanto herramienta para liberar a las sociedades de la eficacia biológica, mientras que los autores de De cuerpo presentese enfocan en la práctica mindfulness como instrumento para corporizar a la falta de fundamento.

Palabras Clave: autopoiesis - enacción mindfulness

\section{Abstract}

The different theoretical positions to which Samaja and Varela, Thompson and Rosch arrive, despite having a common basis in the autopoietic approach proposed by Maturana and Varela, will be analyzed comparatively. In this direction, the argentine author focuses on the importance of normative subjectivity as a tool to liberate societiesfrom biological efficacy, whereas the authors of The Embodied Mind: Cognitive Science and Human Experience direct their attention to mindfulness practice as a way to embody groundlessness.

Keywords: autopoiesis - enaction - mindfulness

Mariano Esteban Saulig es Licenciado en Ciencias de la Comunicación (UBA) y Profesor de Enseñanza Media y Superior en Ciencias de la Comunicación Social (UBA). En la actualidad cursa la Maestría en Estudios Interdisciplinarios de la subjetividad (UBA) y se desempeña profesionalmente como docente de educación media. Orcid 0000-0002-5568-285X. 


\section{Introducción}

En el presente trabajo proponemos un análisis comparativo de los planteos de Samaja y Varela, Thompson y Rosch (1992) con el objetivo de señalar los diversos caminos de reflexión que ambas perspectivas delinean a pesar de tener una base común en el pensamiento autopoiético desarrollado por Maturana y Varela (1986) ${ }^{1}$. En este sentido, la comparación, lejos de ser arbitraria nos parece necesaria; dado que, de hecho, Varela es citado por Samaja en diversas ocasiones, por ejemplo, en la postdata de Epistemología y Metodología, donde señala al investigador chileno como ejemplo de entrecruzamiento de estrategias objetivas de investigación con perspectivas hermenéuticas; es decir, el investigador argentino encuentra en los planteos de De cuerpo presente (Varela, Thompson, Rosch, 1992) cierto apoyo e inspiración para su proyecto neo-dialéctico.

Sin embargo, según nuestra lectura, ambas perspectivas se distancian sustancialmente en que, para Samaja, el centro de la reflexión y de las posibilidades epistemológicas se vinculan a la intersubjetividad normada y los fenómenos adyacentes que ésta pone en juego; mientras que Varela, Thompson y Rosch organizan su reflexión y su postura metodológica en función del camino que les traza la experiencia mindfulness que toman de la tradición budista. En consecuencia, en

1 Este es un trabajo parcial destinado a la producción de una tesis perteneciente a la Maestría en Estudios Interdisciplinarios de la subjetividad (FFyL-UBA). este trabajo señalaremos cómo se erigen estas bifurcaciones teóricas y cómo se expresan en diversos niveles, por ejemplo, en el alcance del concepto de yo, el estatuto que adquiere o mantiene la objetividad, tanto como en el énfasis particular que ambas corrientes le ponen a diversos aspectos del pensamiento kantiano y en las diferentes actitudes y soluciones que esbozan al problema de la caída del fundamento.

\section{La perspectiva de Samaja}

Samaja plantea que el ser humano ha llegado a desarrollar sus características actuales en el seno de una secuencia epigenética, es decir, se ha constituido a partir de los estratos anteriores del ser.

[...] [La epigénesis es un] desarrollo formativo que se levanta, recursivamente, sobre los resultados anteriores. Esto implica que los resultados anteriores contraen ligaduras funcionales con los posteriores, es decir, articulaciones mediante las que las formas anteriores se transforman en partes de los contenidos posteriores, en donde prevalecen unas nuevas formas, y así sucesivamente. (Samaja, 2004, p. 51)

En este sentido, el carácter social del ser humano es un proceso de llegada que incluye las dinámicas físicas, químicas y bióticas previas. Sobre la base de éstas se edifica el ser social del hombre.

En esta dirección, el autor postula que la emergencia de la comunidad cultural fue el primer plano específico del fenómeno humano, y en dicho contexto se logró la liberación de las determinaciones biocomunales, es decir, de las conductas etológicas relacionadas a la experiencia de habitar un ambiente. Éstas fueron reemplazadas por conductas fundamentadas en la cultura. Según Samaja, este proceso se intensificó a partir de la emergencia de las lenguas naturales en 
tanto éstas facilitaron la función eticizante (concepto que toma del biólogo británico C. Waddington), es decir, el proceso de institución de normas en la subjetividad de un individuo:

En efecto, las reglas que la convivencia comunal crea son representadas en la intimidad del psiquismo o de cada individuo mediante numerosos y potentes recursos semióticos, de los cuales, las lenguas naturales son, precisamente, las portadoras más expresivas de las expectativas de los roles a cumplir. (Samaja, 2004, p. 58)

conducta humana. Según el autor, la centralidad que ha cobrado la sociedad civily la emergencia de instituciones que pretenden limitar el poder del Estado suponen el último peldaño (hasta el momento) en la secuencia epigenética, por lo que constituyen "el más reciente estrato de liberación humana" (Samaja, 2004, p. 66).

\section{Libertad, autonomía, lógica epigenética}

Sostener una postura epistémica de base epigenética supone admitir la variabilidad de los sistemas y la posibi-

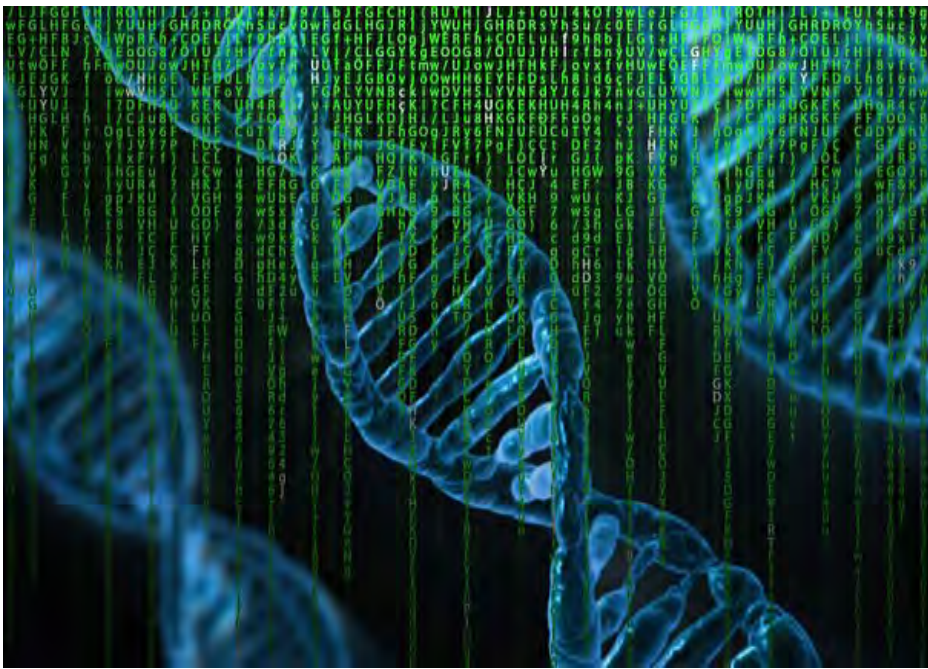
lidad de emergencia de nuevos estratos, es decir, de saltos cualitativos. En este sentido, para señalar su postura epistemológica, Samaja parte de la diferenciación respecto de la posición positivista. Según su lectura, ésta suponela idea de que los fenómenos naturales no realizan ningún fin o valor, es decir, no producen auto-evaluaciones de las posibilidades ambientales en función de una lógica interna, sino que operan

En esta dirección, para el autor, el posterior desarrollo de la escritura expandió la potencia de la función eticizante más allá del contacto cara a cara. En consecuencia, dado el nuevo alcance de la eficacia normativa, el hombre pudo pasar de la comunidad cultural a la Polis.

En la perspectiva de Samaja, la emergencia de la Polis o el Estado, supone un paso más en la secuencia epigenética que en este caso viene a superar las determinaciones que la comunidad cultural operaba sobre el hombre, al paso que el mismo se transformó en el nuevo fundamento de la en un determinismo que depende de leyes inexorables vinculadas a condiciones iniciales. En cambio, el autor de Epistemología de la salud, a partir de un conjunto de teorías científicas y hallazgos empíricos tales como la termodinámica de los sistemas disipativos, la teoría del caos determinístico, la concepción autopoiética en Biología (Maturana y Varela, 1986), entre otros; plantea:

[Estos hallazgos] han obligado a reconocer que el universo no está integrado meramente por materia y energía, sino, también por información, por orden, es decir, por unas determinadas diferencias 
entre los componentes, y por determinadas relaciones entre esas diferencias lo que hace emerger la capacidad de los hechos mismos de llevar a cabo procesos de clasificación, codificación, registro y transmisión de información. (Samaja, 2004, p. 53)

Es decir, en particular, Samaja subraya la existencia de cierta autonomía en cada estrato epigenético dotada de cierto poder de eficacia para poner en marcha reacciones que no son una mera reactividad a las condiciones externas, sino producto de una evaluación o una especie de protoevaluación. En esta línea, el autor señala que en cada estrato esa autonomía varía en potencialidad, partiendo desde el estrato de los fenómenos físicos y termodinámicos en el quelos elementos interactuantes muestran el menor nivel de autonomía:

Los valores medios (o "normas") que caracterizan un cierto ordenamiento físico-químico están, en consecuencia, determinados fuertemente por el medio externo. Podría decirse, por tanto, que poseen estructura autónoma, pero, no poseen organización autónoma (son jerarquías estructurales pero no funcionales; son estructuras pero no organismos). (Samaja, 2004, p. 57)

Este estrato es seguido en la secuencia por los fenómenos bióticos, que el autor analiza como "autopoiéticos", es decir, como manidos de un nivel de autonomía que les permite estructurar una organización estable que en parte no depende del medio externo, aunque dicha autonomía es analizada como aún limitada respecto del medio, dado que en el largo plazo, la autorregulación que la especie generó a partir de la inscripción en el código genético sigue dependiendo del medio. El siguiente paso en la secuencia, como antes se ha dicho, supone la aparición de la cultura como estrato limitador de la determinación de naturaleza biológica.

En este sentido, a los fines de este trabajo, es importante señalar que la auto- nomía en cada estrato supone un nivel de información en tanto hay una estructura u organismo que es capaz de evaluar una variabilidad en el seno de una dimensión propia que está dotada de la posibilidad de captar variabilidades en función de sus propias características fenomenológicas de detección. En esta dirección, el centro del esquema de análisis que desarrolla Samaja propone que el salto cualitativo entre estratos supone un incremento en la capacidad de control de los propios contenidos afectados por variabilidades. Así, aquellos contenidos que en un nivel son determinantes pierden su eficacia ante la emergencia de un nuevo estrato, que a su vez, genera nuevas determinaciones que escapan al control del estrato emergente. Un ejemplo, es el concepto de hombre anterior al contrato social que imaginó el pensamiento moderno clásico, aquél individuo estaba al servicio de la violencia de su propia naturaleza, mientras que la emergencia del contrato social supuso en dicha perspectiva una regulación conductual basada en un nuevo contenido, la norma, fenómeno humano existente como información para el nuevo hombre racional-social-moderno:

La vida humana implica no sólo la conciencia, sino también la autoconciencia, o conciencia recognoscitiva. Entiendo por tal esa forma de conciencia que se constituye por mediación del reconocimiento jurídico de cada quien en el marco de instituciones sociales. El estrato del ser social, inherente al ser humano contiene, pues, como dimensión que corona los desarrollos biológicos, psicológicos, económicos y sociales, la dimensión jurídica, es decir, la esfera de las relaciones de reconocimiento, o, lo que es lo mismo, relaciones de derecho. (Samaja, 2004, p. 62)

Según Samaja, todo estrato emergente al generar nuevas determinaciones también se instituye como nuevo fundamento por lo que en dicho proceso se expresa como un ser-ahí, es decir, como inscripción en una dogmática 
vivencial que se autoimagina como fin último, es decir, como fundamento absoluto; aunque dicha percepción es solo fenoménica dado que la potencial emergencia de un nuevo estrato transformaría inmediatamente al anterior fundamento absoluto en relativo, tal como éste hizo con los estratos inferiores en el momento de su emergencia.

En esta dirección, el autor propone que esta capacidad de autonomía emergente en tanto control de elementos se corresponde con su definición de libertad, por lo que ésta es pensada, no como una sustancia que pueda hallarse en alguna dimensión del ser, sino como una función que opera en las interfaces jerárquicas de los estratos (Samaja, 2004, p. 65).

La centralidad que cobra, en la perspectiva de Samaja, la condición de ser social que presenta el humano en el último estrato de la secuencia epigenética en tanto individuo sujetado a la presencia de otros individuos mediante el vínculo que establece la norma se expresa también en la lectura que el investigador realiza de Vico y Kant:

[...] las estructuras del Entendimiento son, en Vico y en Kant, el precipitado de la milenaria experiencia jurídica (o moral, en sentido amplio)... En esa experiencia moral se ha constituido la subjetividad humana (Samaja, 2004b, p. 65).

\section{Vico}

En la propuesta filosófica de Vico, Samaja encuentra un antecedente de la perspectiva epigenética piagetiana debido a que el pensador italiano afirmaba que el sujeto racional era producto de un proceso histórico de desarrollo. Es decir, en su postura hay un primado del sujeto práctico, que a partir de contingencias sociales, incluidas batallas de toda índole, comenzó a desarrollar sistemas de normas que fueron estabilizándose en el tiempo. El investigador argentino señala que Vico sostenía la tesis de que, en el largo plazo, todas las sociedades habían generado ordenamientos que avanzaron en una misma dirección, aún cuando cada pueblo engendró sistemas de normas particulares en función de los diversos accidentes históricos que enfrentó:

Las ideas uniformes nacidas en pueblos desconocidos entresí deben tener un motivo deverdad. [...] El derecho natural delas gentes nace privadamente en los pueblos sin saber nada uno de los otros; y después, con ocasión de las guerras, embajadas, alianzas, comercio, se reconocería común a todo el género humano. (Citado en Samaja, 2004b, p. 66)

En este sentido, la perspectiva histórica del filósofo italiano supone que la emergencia de la razón es el último estadio de un desarrollo progresivo que coincidió con el momento en el que las relaciones jurídicas se extendieron a toda la sociedad.

\section{Kant}

Según Samaja, si bien Kant parte del yo pienso moderno para dar cuenta de las formas de la sensibilidad y de las categorías del intelecto, éste encuentra una manera completamente distinta de trascender al solipsismo que amenaza al cogito:

[...] si el Yo no tuviera una relación de derecho sobre sus representaciones, él no se habría constituido, él no podría volver una y otra vez sobre sus representaciones como sobre un mismo contenido, y, consecuentemente, él no se habría constituido y no podríamos ni siquiera estar hablando de él.(Citado en Samaja, 2004b, p. 68)

En este sentido, el investigador argentino afirma que la autoconciencia es más que una vivencia breve (algo que caracteriza como grado inferior de conciencia), sino que supone una relación de propiedad con el 
objeto, que puede continuarse y convocarse según la propia voluntad del individuo.

En esta dirección, según la lectura de Samaja, Kant postula que dicha estructura es consecuencia de una experiencia práctica y moral del yo, dado que el sujeto práctico es producto de la ley de reconocimiento de los otros yoes, en tanto éstos no se erigen como factores que pongan en tela de juicio a la potestad de las representaciones del yo. Por ello, según Samaja: “[...] en el yopienso (como sujeto cognoscente) hay pues una estructura jurídica ideal" (Samaja, 2004b, p. 68)

En consecuencia, el investigador argentino caracteriza como erróneas a las lecturas que restringen la epistemología elaborada por Kant sólo a los planteamientos desarrollados en la Crítica de la Razón pura en torno a las tesis sobre las intuiciones y categorías puras, sino que propone que éstas encuentran su fundamento en la libertad humana, por lo que la epistemología kantiana sería inseparable de su teoría moral y antropológica. Por ende, para Samaja la propuesta del filósofo alemán fue la primera epistemología sistemática de la praxis, en tanto el investigador argentino encuentra en ésta un concepto juridiforme de praxis que piensa a la conducta humana como relación de derecho, es decir, en interferencia intersubjetiva (Samaja, 2004b, p. 69).

\section{Cossio}

Además de Kant y Vico, otro afluente teórico que fundamenta la posición de Samaja en torno a la eficacia subjetiva de la norma en tanto lazo intersubjetivo es la teoría jurídica de Carlos Cossio. Según el pensador argentino, el objeto de la ciencia jurídica es el estudio de la "[...] conducta que se integra con la vivencia de la norma" (citado en Ynoub, 2016, p. 62), dicha afirmación resalta la importancia del reconocimiento de la ley, amén de su aceptación o incumpli- miento, ya que la interpelación de la norma transforma, en el seno de la subjetividad del individuo, a una mera acción potencial en una acción lícita o ilícita. En esta dirección, Cossio planteó el carácter social de la experiencia jurídica, en tanto la eficacia del sistema normativo depende de la existencia de un nosotros, o comunidad legitimante, sobre la que se delegan las atribuciones de derechos y obligaciones.

El jurista planteó que toda norma supone, en sí misma, la existencia de la endonorma y la perinorma. La primera remite a la regulación que garantiza un derecho, por ejemplo la propiedad de un espacio suscripta a un individuo, y que al mismo tiempo impone la obligación de reconocimiento a los otros individuos; mientras que la perinorma establece la sanción por incumplimiento tanto como al agente designado (funcionario obligado) por la comunidad legitimante para dar curso a la punición. Esto es de particular interés para Samaja, dado que marca un salto ontológico-epigénetico que pasa del individuo al grupo:

Si nuestro nivel de anclaje son los individuos, entonces la comunidad no aparece como un sujeto real (en el sentido de que ella no es un 'individuo de carne y hueso'), sino un sujeto ideal. Pero si nuestro nivel de anclaje es el grupo entonces, él es, a su turno, también un ser real: en este caso, los individuos pasan a ser partes no separables del todo. (Samaja, 2004b, p. 327)

\section{El enfoque enactivo en De cuerpo presente}

Varela, Thompson y Rosch (1992) formularon su perspectiva enactiva en el marco de las ciencias cognitivas. En dicho contexto, el investigador chileno y sus colegas problematizaron el enfoque dominante en el campo, ya que éste postulaba a la mente como un ordenador simbólico dado mientras 
que éstos propusieron el enfoque enactivo para criticar la centralidad del concepto de representación como supuesto explicativo de los fenómenos cognitivos. Su posición se apoya en dos críticas a esta postura dominante. Por un lado, junto a las perspectivas emergentistas postulan que los procesos cognitivos se ponen en marcha a partir de sistemas integrados que conectan diversos componentes no localizados mientras que la teoría cognitiva dominante se apoya en el procesamiento local de símbolos dado que los cómputos operarían por la detección de símbolos, no por su significado. Por otra parte, la segunda crítica remite a la mencionada noción de representación. Según Varela y sus colegas, tomar dicha noción como pivot conceptual supone tres supuestos: el mundo presenta propiedades como el color que existen más allá de quién las experimenta; en segundo lugar, el ser humano en su cotidiano existir recobra estas propiedades a partir de representaciones internas; y por último, habría una instancia subjetiva separada ocupada de llevar a cabo dichas tareas.

\section{Noción de experiencia}

Varela, Thompson y Rosch convocan al concepto de experiencia prestando atención a la tradición de la fenomenología. Para delinear su posicionamiento parten de mencionar que la filosofía de la mente presente en el pensamiento de Descartes alcanzó su cenit en los trabajos de Brentano. Según el investigador chileno y sus colegas, el primero elaboró una noción de conciencia subjetiva deudora del concepto de representación, en tanto los contenidos de ésta podían corresponderse o no con el
En esta línea, el enfoque enactivo es propuesto como forma de evadirse de los supuestos mencionados en tanto, según los investigadores, empujan a la ciencia al irresoluble dualismo objetivismo/subjetivismo. En consecuencia, los autores postulan el enfoque enactivo para desarrollar una perspectiva que estudie a la cognición, ya no como representación de un mundo pre-dado, sino como "[...] la puesta en obra de un mundo y una mente a partir de una historia de la variedad de acciones que un ser realiza en el mundo" (Varela et al., 1992, p. 33). En este sentido, cabe subrayar que entender el acento o la significación que carga la palabra acción en la perspectiva de los autores es central para comprender su propuesta dado que es pensada como experiencia. estado de cosas presentes en el mundo. El segundo, por su parte, delineó el concepto de intencionalidad que postula que todos los estados mentales son conciencia de algo. Según la lectura de Varela, Thompson y Rosch, esa conciencia de algo es en referencia a algún contenido por lo que éstos también encuentran a la noción de representación en la conceptualización propuesta por el filosófico austríaco.

En la misma dirección, Varelay sus colegas reconocen el esfuerzo que realizó Husserl para trascender lo que éste denominaba realismo ingenuo, es decir, la convicción de que la realidad del mundo es independiente de la mente. En este sentido, los autores de Decuerpo presente afirman que la epoche, es 
decir, el intento de analizar la experiencia sin referencia al mundo fáctico, fracasó debido a que, en tanto, conocimiento también racional y filosófico, la fenomenología quedó entrampada dentro de la circularidad fundamental dado que al reflexionar sobre los procesos intencionales sin referencia al mundo, aún necesitaba, de forma infinitamente recursiva, tener en cuenta al mundo de la vida. En esta dirección, los investigadores encuentran que también la propuesta del filósofo francés tropieza con el concepto de representación:

Husserl reconoció parte de esta circularidad y procuró abordarla de una manera interesante. Argumentó que el mundo-vida era un conjunto de pre-entendimientos de fondo sedimentados o (por usar una palabra imprecisa) supuestos, que el fenomenólogo podía volver explícitos y tratar como un sistema de creencias. En otras palabras, Husserl trató de salir del círculo tratando el trasfondo como si consistiera esencialmente en representaciones. (Varela et al., 1992, p. 42)

En la misma dirección, la última posta de la historia filosófica occidental que el investigador chileno y sus colegas analizan para mapear al problema de la experiencia vinculado a la representación, es el pensamiento de Merleau Ponty. Del filósofo francés reconocen que si bien éste asumió el problema del carácter post-factum de todo conocimiento filosófico occidental, y por ende intento estudiar el carácter no reflexivo de la experiencia humana, no pudo dar con "la riqueza" de la experiencia debido que sus análisis también eran post-factum (Varela et al., 1992).

Para salir de los problemas que genera la circularidad fundamental, los autores proponen prestarleatención a las doctrinas budistas. Encuentran que pueden buscar ese apoyo dado quelas ideas deno-yoy no-dualismo son pasibles de establecer un diálogo con el cognitivismo ya quela idea de no-yo es similar a la elaborada por el emergentismo en torno a la no existencia de un yo fijo (preocupación que como veremos ha estado presente en la tradición occidental, incluso en Kant); mientras que el no-dualismo vislumbran que puede relacionarse a la noción de entre-deux propuesta por Merleau Ponty. En esta línea, Varela, Thompson y Rosch remarcan que las corrientes filosóficas budistas y también las hindúes nunca se basaron solamente en reflexiones abstractas, sino que éstas siempre estuvieron supeditadas a métodos disciplinados. De esta manera, lo que principalmente toman en cuenta es que en la tradición budista la práctica de la meditación ocupa un lugar central, en particular aquella que propicia el estado de mindfulness o presencia plena/conciencia abierta:

Presencia plena significa que la mente, en efecto, está presente en la experiencia corpórea cotidiana; las técnicas de presencia plena están diseñadas para retrotraer la mente desde sus teorías y preocupaciones, desde la actitud abstracta, hacia la situación de la propia experiencia. (Varela et al., 1992, p. 46)

Lo que interesa a los autores, y a este trabajo, es la aparición de un desnivel en el pensamiento, que permite pensar la cognición pero desde una actividad mental que no es propiamente un pensamiento:

El cuerpo está sentado pero la mente es ocupada constantemente por pensamientos, sentimientos, conversaciones interiores, ensueños diurnos, fantasías, sopor, opiniones, teorías, juicios sobre pensamientos y sentimientos, juicios sobre juicios, un torrente incesante de acontecimientos mentales inconexos en los que el meditador no repara excepto en esos breves instantes en que recuerda lo que está haciendo. Aun cuando intenta regresar al objeto de su presencia plena, la respiración, descubre que sólo piensa en la respiración en vez de estar alerta a la respiración. (Varela, et al., 1992, p. 50)

Según el budismo ${ }^{2}$, ese estar alerta es una capacidad que se genera con la práctica, y que

2 Varela, Thompson y Rosch adscriben a la definición y procuran sostenerla desde una perspectiva científica. 
paulatinamente propicia que el practicante note como usualmente está desconectado de su propia experiencia, es decir, de tener la capacidad de auto-observar los procesos que lleva a cabo $s u$ mente. En este sentido, el investigador chileno y sus colegas remarcan que la actitud abstracta que criticó toda la fenomenología, y que Heidegger y Merleau Ponty le atribuyen a la ciencia y la filosofía, en realidad es el estado constante en el que vive el ser humano cada vez que no está alerta. En consecuencia, los investigadores proponen una salida práctica/pragmática, tanto a nivel ético como metodológico (ya que su postura llevó posteriormente a la elaboración del programa neurofenomenológico), basada en la transformación de las reflexiones, es decir, de actitudes abstractas (teoría sobre la experiencia) pasar a reflexiones que son experiencias en sí mismas.

Por último, cabe destacar que los autores sostienen que esta perspectiva de inspiración budista tiene cierto correlato entre los occidentales en el psicoanálisis, no por el corpus teórico o metapsicológico que esta disciplina pone en juego, sino porque la práctica del análisis procura generar una transformación de la mente del analizando al paso de que se indaga la estructura de sus representaciones.

\section{La experiencia del yo}

El edificio teórico que construyen Varela, Thompson y Rosch, incluye una noción fenoménica del yo, es decir, ilusoria en tanto no unificada. En este punto encuentran coincidencias entre la perspectiva budista y la moderna, aun cuando ambas corrientes salen del problema de diversas maneras:
Deseamos hacer una afirmación general: todas las tradiciones reflexivas de la historia humana-filosofía, ciencia, psicoanálisis, religión, meditación— han desafiado la noción ingenua del yo. Ninguna tradición sostiene haber descubierto un yo independiente, fijo o unitario dentro del mundo de la experiencia. (Varela, et al., 1992, p. 83)

En el budismo, la problemática del yo es central ya que la ilusión de preservarlo, dada la suma de deseos que trae ańadido, son señaladas como la causa del sufrimiento. En esta línea, el yo es analizado en una lógica de sujeto-objeto de modo que cada vez que actualiza su eficacia lo hace en función de algún objeto:

La idea es que, en la medida en que los seres son presa de hábitos yoístas', los objetos, ora físicos o mentales, se disciernen, aun en el primer instante de la relación con el yo, como deseables, indeseables o irrelevantes para el yo, y en ese mismo discernimiento está el impulso automático de actuar de manera relevante.(Varela, et al, 1992, p. 91)

En esta dirección, Varela destaca que en dicha tradición, amén de profundos debates, hay acuerdo en que cada objeto supone un sujeto diferente, es decir, que los objetos percibidos ponen en marcha conciencias diferentes en función de los sentidos que participan de su enacción. Además agrega, de particular importancia para este trabajo, que el budismo supone dos formas de conocimiento: la conciencia vijñana, que equivale al yo objetual recién descripto y a una forma alternativa de conocer denominada prajña, que no conoce a través de la relación sujeto/objeto.

Respecto de la problemática del yo en las perspectivas occidentales, Varela y sus colegas postulan que éstas le escapan echando mano 
de dos tácticas: simplemente ignorarla al estilo Hume, o postulando una instancia trascendental inaccesible por vía de la experiencia. En esta línea, los investigadores sostienen que en la obra Kant se reconoce "[...] la ausencia de un yo sustancial en la momentaneidad de la experiencia" (Varela, et al., 1992, p. 96), aunque con el trasfondo de que el filósofo escapa a la crisis del fundamento a partir del planteamiento del sujeto trascendental en tanto conciencia pura e inmutable, por lo que ubican a la obra de Kant entre las tradiciones que optaron por la segunda táctica. Para apoyar dicha lectura señalan el siguiente pasaje de la Crítica de la razón pura:

La conciencia del yo, de acuerdo con las determinaciones de nuestro estado en la percepción interior, es meramente empírica, y siempre cambiante. Ningún yo fijo y permanente se puede manifestar en este flujo de apariencias internas... [Así pues] debe haber una condición anterior a toda experiencia, la cual posibilite la experiencia misma... Llamaré apercepción trascendental a esta conciencia pura, original e inmutable .(citado en Varela, et al., 1992, p. 95)

Según la lectura de los autores, en este fragmento Kant profundiza las dificultades ya que postula un yo inaccesible y separado de la experiencia, por lo que se preguntan cómo puede ser fundamento de las experiencias individuales si a la vez no es modificado por éstas:

[...] si de veras existe ese yo, sólo puede ser relevante para la experiencia si comparte la dependencia que constituye la estofa del mundo, pero en tal caso obviamente violaría su condición prístina y absoluta. (Varela, et al., 1992, p. 96)

En consecuencia, los investigadores sostienen que la perspectiva del filósofo alemán coincide con la tradición de la presencia plena/ conciencia abierta en que también señala el carácter fugaz del yo de la experiencia, aunque ambas corrientes se separan en el plano del sujeto trascendental, ya que la perspectiva de la presencia plena impulsa a los practicantes a ceñirse a la fugacidad de este $<<$ yo $>>\sin$ echar mano de alguna instancia trascendente de consciencia.

En esta línea, Varela y sus colegas encuentran, en la separación del campo fenoménico en tanto comarca de la verdad de la dimensión noumenal, caracterizada por Kant como "[...] borrascoso océano [...] donde muchos bancos de niebla y témpanos que se derriten de prisa ofrecen la engañosa apariencia de costas más lejanas [...]" (citado en Varela et al., 1992, p. 169), la expresión de la angustia cartesiana ante la crisis del fundamento, que según su lectura, exhiben las tradiciones occidentales. En cambio, a partir de los planteos de Nagarjuna, los autores proponen superarla, para, entre otras cosas, obturar el peligro del nihilismo que acecha a las tradiciones occidentales modernas desde el pensamiento de Descartes.

Por último, cabe destacar que Varelay sus colegas optan, entre la solución kantiana y la budista, por la segunda; debido a que (como vimos en el apartado sobre la experiencia) les permite postular la atención a la experiencia en tanto aquí y ahora, deslindada de un yo que se escapa hacia otras temporalidades o conceptos, sin necesidad de recurrir a una instancia integradora conceptual como el sujeto trascendental que es por definición inaccesible a la experiencia.

\section{Concepto de enacción}

En línea con la crítica a la noción de representación antes desarrollada, el enfoque enactivo parte del estudio de cómo el individuo que percibe puede administrar el proceso, es decir, la percepción no aparece determinada a priori por el contexto, sino que hay un espectro de mayor o menor variabilidad que depende del perceptor. En consecuencia, según Varela, las situaciones locales cambian 
en función de las acciones perceptivas del perceptor. Hay que subrayar el hecho de que éstas solo tienen la capacidad de modificar la situación local en cierta medida, dado que el enfoque enactivo procura ser una vía media entre el subjetivismo y el objetivismo, algo que los autores ejemplifican con los estudios del color (Varela, et al., 1992, p. 202).

Como es evidente, el concepto de enacción supone desde un principio que el conocedor y lo conocido, o el sujeto y el objeto, se definen mutuamente. Pero, en este caso, los objetos no sólo son producto de un sujeto epistémico sino que éstos son perceptivos, por lo que las enacciones de los objetos son puestas en marcha por sujetos compuestos de emergentes que incluyen diversas dimensiones, entre ellas la cultural, pero no sólo, dado que también concitan aptitudes sensorio-motoras disponibles en el cuerpo perceptor. En este sentido, el enfoque enactivo descansa sobre lo que los autores denominan giro acción corporizada, que supone una perspectiva en la que los procesos cognitivos dependen de la posesión de un cuerpo dotado de aptitudes sensorio-motrices; que varían de individuo a individuo ( $y$ en el tiempo en un mismo individuo) en función de su propia experiencia, programas de entrenamientos en los que se haya embarcado, disposiciones psicológicas, entre otras. Así, si bien hay co-determinación sujeto-objeto, siempre parece haber un cierto poder de eficacia mayor en elpolo del sujeto, aunque con la necesidad de destacar que el enfoque enactivo procura posicionarse en el medio de los polos:

Esta estructura -el modo en que está corporizado el perceptor, no un mundo pre-dado- determina cómo el perceptor puede actuar y ser modulado por acontecimientos ambientales. El enfoque enactivo de la percepción no procura determinar cómo se recobra un mundo independiente del perceptor, sino determinar los principios comunes de ligamiento legal entre los sistemas sensoriales y motores que explican cómo la acción puede ser guiada perceptivamente en un mundo dependiente del perceptor interno. (Varela et al., 1992, p. 203)

El ligamiento legal es la puerta que tiene el enfoque para construir estrategias metodológicas en el seno de la ciencia. Su potencialidad se relaciona a la teoría de las emergencias que subyace al planteo, es decir, a la idea de que el funcionamiento cerebral está basado en la interacción de subsistemas que se van constituyendo y volviendo disponibles como consecuencia de la experiencia. De esta manera, los patrones disponibles por un cuerpo son pasibles de emerger ante una situación particular, y en función de ese emerger, se da la percepción que organiza la situación local; o en otras palabras, destacan objetos, que surgen en co-determinación con la instancia subjetiva emergente. En esta línea, pueden hallarse principios de ligamiento legal si se logra correlacionar un emergente-enactuante con un objeto enactuado.

La cantidad de emergentes-enactuantes posibles tiende a un número inabarcable dadas las cantidades de neuronas y posibles interconexiones que éstas posibilitan, si solo atendemos al nivel cerebral, dado que la teoría de la enacción es de orden mental, en tanto observa al cerebro como expresión de la mente y no como instancia fundamental de la corporización, por lo que las posibles emergencias pueden ser, al menos a nivel teórico, más que las neuronas y sinapsis disponibles. Sin embargo, la abrumadora esfera de la potencialidad no nos impide señalar algunos emergentes tangibles. Por ejemplo, podemos mencionar aquellos que surgen como consecuencia de lesiones neurológicas o perfiles más eficientes de procesamiento de inputs, como es el caso de los grandes performers (ya sean deportistas o artistas), que parecen tener la capacidad de procesar la información perteneciente a su desempeño en una temporalidad diferente (capacidad de tocar notas musicales en un músico, o de 
percibir espacios a partir de cambios de ritmos en el deporte, etc.). De esta enorme gama de posibilidades, el emergente-enactuante que más nos interesa trabajar, en el contexto de este trabajo, es el $y o$.

\section{El yo como emergente-enactuante}

En esta línea, Varela, Thompson y Rosch ensayan un cruce de su perspectiva con el psicoanálisis vía la teoría de las relaciones objétales, a la que señalan como una expansión del concepto de superyó en tanto ésta permitiría incluir la internalización de una amplia gama de personas que condicionarían la conducta del individuo. De esta manera, el vínculo con las personas, así como las situaciones traumáticas, tanto como la subjetivación vía la cultura y el marketing, pueden ser leídos como emergentes que se vuelven disposicionales en una persona, y por ende, capaces de activarse como emergentes-enactuantes en alguna situación local particular. Como antes vimos, el investigador chileno y sus colegas trabajan con la idea de que el sentido unitario del yo es fenoménico, y en este sentido, compuesto por una suma de emergentes solo agrupados de modo ilusorio.

En esta dirección, lo que los autores suman a esta perspectiva es la posibilidad de amplificar la conciencia mediante el desarrollo de mindfulness, por lo que señalan:

[...] nadie está investigando los modos en que la aprehensión consciente se puede transformar gracias a prácticas tales como la presencia plena/consciencia abierta. En la tradición de la presencia plena/consciencia abierta, en cambio, la posibilidad de dicha transformación es la piedra angular del estudio de la mente (Varela et al., 1992, p. 155).

En esta posición subyace una ética de inspiración budista que incluye la idea de que el sufrimiento es producto del apego (la falta en términos psicoanalíticos), que es básicamente aquello que define al yo. Lo interesante de esta perspectiva, es que el estado mindfulness, se plantea como una auto-observación individual que permite detener la cadena del apego que los budistas retratan con la rueda de la vida. En ésta, el momento ocho denominado "afán", es aquél en el cual la persona puede detener su impulso (producto del emergente-enactuante) a expresar-experimentar el apego hacia el objeto, y no solo puede detenerlo, sino que puede tomar consciencia del carácter fenoménico de dicha relación sujeto-objeto y por ende del sufrimiento que ésta acarrea. En este sentido, nos interesa subrayar que mindfulness $o$ presencia plena/consciencia abierta es un tipo de emergente que se puede alcanzar en base al entrenamiento, y que una vez logrado, tiene la capacidad de observar y controlar a los emergentes yoicos, entre ellos los superyoicos. Para el presente trabajo esto es de vital importancia dado que supone una capacidad individual de atenuar la presencia de los otros en el individuo, ya sea en referencia a situaciones traumáticas, mandatos superyoicos familiares, tanto como a interpelaciones de la cultura o del contrato social.

\section{El enfoque enactivo y la caída del fundamento}

El planteo de las ciencias enactivas es propuesto como una salida alternativa al problema de la caída del fundamento moderno. En este sentido, Varela y sus colegas sostienen que el descubrimiento meramente teórico de la mente sin yo lleva al nihilismo:

Si la ciencia continúa manipulando cosas sin evaluar cómo vivimos entre esas cosas, el descubrimiento de la mente sin yo no tendrá vida fuera del laboratorio, a pesar de que la mente que está en ese laboratorio sea también una mente sin yo . (Varela et al., 1992, p. 155) 
En esta dirección, los autores destacan que los métodos de la ciencia tradicional carecen de herramientas para corporizar la falta de fundamento. Cuando los autores utilizan la expresión "corporizar", la usan en el sentido que le asignó Merleau Ponty, es decir, que la corporización no solo incluye al cuerpo como experiencia vívida sino también incluye a la cognición. De esta manera, Varela y sus colegas sostienen que si no se corporiza la falta de fundamento, no se puede detener el impulso a buscarlo aún a sabiendas de la imposibilidad de hallarlo. En consecuencia, el camino al nihilismo queda allanado. Esta carencia de herramientas de corporización remite a que la construcción de conocimiento en Occidente, tanto en la ciencia como en la filosofía, es producida por el emergente-enactuante yo pienso. En este sentido, según nuestra lectura, la corporización que los autores le sugieren a la ciencia, y que encuentran en las prácticas mindfulness, propician un desnivel enactuante que por su eficacia trasciende al nihilismo.

Por tanto, Varela y sus colegas suscriben el concepto de nihilismo que aportó Nietzsche en La voluntad de poder, es decir la afirmación de que nuestros valores más apreciados, es decir, aquellos que sustentan nuestra visión de la vida y la experiencia cotidiana son insostenibles, con la complejidad de que nuestros sistemas experenciales no pueden renunciar a éstos. Según la perspectiva enactiva de los autores, sucede que cada vez que procuramos encontrar un sustento fijo en el afuera, solo encontramos objetos que emergen de la co-determinación, es decir, no absolutos. En consecuencia, los autores afirman que el nihilismo es producto del fracaso del objetivismo.

En este orden, los autores reflexionan sobre el alcance que tiene para la vida cotidiana el problema de la caída del fundamento. Parten de aclarar que el hecho de la caída del fundamento y la consciencia teórica de la no existencia de objetos pre-dados no suponen negar al realismo metafísico ni al realismo empírico. Sin embargo, sostienen que es importante señalar la existencia de dos tipos de realismo empírico; por un lado, aquél que refiere a la idea de que seguirán existiendo objetos y acontecimientos con cualidades amén de que sostengamos el carácter predado de los fenómenos; por otro, la idea de que la humanidad está condenada a existir suponiendo el como si del fundamento, a pesar de que sepa de su inexistencia. Respecto de este segundo tipo, afirman que no es inocente, ya que acarrea como consecuencia una limitación a priori de las posibilidades de transformación de la experiencia humana.

Por ende, los autores de De Cuerpo presente, se apoyan en la lectura Keiji Nishitani quien apoya el gesto deconstructivo del fundamento que realiza Nietzsche, aunque se diferencia de éste en que considera que las salidas propuestas por el filósofo alemán, a partir de la voluntad de poder y la tesis del eterno retorno. El filósofo japonés afirma que no puede superarse el nihilismo apostando a la noción de voluntad por más des-centrada que esta sea. En esta dirección, sostiene que el recurso nietzscheano es insuficiente porque no permite deslindarse de la mente apegada. Por consiguiente, según nuestra lectura, las soluciones elaboradas por Nietzsche siguen siendo una enacción puesta en marcha por el mismo emergente que genera y procura fundamentos. Según Varela et al.:

El diagnóstico de Nishitani es aún más radical que el de Nietzsche, pues afirma que el verdadero problema del nihilismo occidental es su falta de atrevimiento: no sigue con coherencia su propia lógica y motivación internas, y así no logra transformar su parcial comprensión de la falta de fundamento en las posibilidades filosóficas y experienciales del sunyata. La razón por la cual el nihilismo occidental se atasca en el camino es que el pensamiento occidental no tiene una tradición que trabaje directa y pragmáticamente con 
la cognición y la experiencia vivida .(Varela, et al., 1992, p. 278)

El concepto tibetano sunyata significa "vacuidad", entre otras dimensiones, respecto del origen co-dependiente de los objetos. El carácter vacío de los objetos responde a que su significación se apaga si no está presente el sujeto que la enactúa en el seno de una relación co-dependiente. Vacío, en este sentido, significa no absoluto o dependiente: "[...] por definición, algo es independiente, intrínseco o absoluto sólo si no depende de nada más; debe tener una identidad que trascienda sus relaciones" (Varela et al., 1992, p. 258). Como antes vimos, Varela y sus colegas no pretenden llevar la crisis del fundamento a una noción que niegue el realismo metafísico y el empírico, por lo que, según nuestra lectura, el carácter no identitario de un objeto no remite a su caducidad o perpetuidad fenoménica material, sino a su significación. Decimos fenoménica material, porque desde perspectivas cuánticas, amén de polémicas en torno del asunto, se supone que la percepción también es co-determinante a nivel de partículas subatómicas. De todos modos, Varela y sus colegas sistemáticamente se diferencian de esas posturas cuánticas para obturar el riesgo de un subjetivismo ingenuo todo creador, y a la vez, porque la física cuántica sigue siendo un concepto teórico enactuado exclusivamente por el sujeto de la ciencia mientras que ellos apuestan por sumar al dato experiencial en los programas metodológicos.

En esta dirección, los autores sostienen que en el budismo afirmar que todo es dependiente ayuda a evitar el nihilismo y el absolutismo. Según la lectura de los autores de Decuerpo presente, este planteo de la tradición budista no supone un intento de establecer una teoría metafísica de la realidad sino que es la descripción de las experiencias que se suscitan en la mente de los practicantes. En consecuencia, afirman:
Cuando Nishitani observa que el nihilismo occidental no llega a la falta de fundamento de la vía intermedia, no está diciendo que debiéramos adoptar el budismo en el sentido de una tradición particular con sus características culturales, sino que debemos lograr una comprensión de la falta de fundamento como vía intermedia a partir de nuestras propias premisas culturales. Estas premisas están determinadas en gran medida por la ciencia, pues vivimos en una cultura científica. (Varela et al., 1992, p. 279)

Porotra parte, el enfoque abierto yalerta, en la opinión de los autores, genera la posibilidad de tomar consciencia de que el yo que emerge, siempre lo hace en relación a un otro, en tanto que por su propia constitución, las cosas que procura el yo solo puede encontrarlas en otros, por ejemplo, el deseo de reconocimiento. En esta dirección, la lógica subyacente a la conceptualización enactiva, vinculada a la carencia de fundamento debido a la vacuidad de todos los objetos, se apoya también en una posición hacia los otros basada en la compasión que los autores toman también del budismo. Si bien es un cierto tipo deactitud ética, no lo es en el sentido clásico, dado que no es un mandato cultural-individual al estilo kantiano: " [...] obrar de tal manera que la acción de cada sujeto sea compatible con el reconocimiento de los vínculos de los otros sujetos" (citado en Samaja, 2004b, p. 71), sino que surge debido a que la vacuidad estaría llena de compasión. Según nuestra lectura, esto es: en tanto el emergente-enactuante que es capaz de vivenciar la vacuidad de todo fenómeno co-determinado es distinto al yo cotidiano no-alerta, una de las consecuencias enactivas inmediatas es la vivencia de una compasión práctica, es decir, no teórica, no enraizada en cierto tipo de fundamento discursivo quela promueve, sino simplemente vívida. Esto, Varelay sus colegas lo detectan en la tradición del budismo:

El budismo positivo es amenazador. No tiene la menor solidez y no se lo puede aferrar como fundamento, punto de referencia o refugio para el yo. No existe, 
pero tampoco deja de existir. No puede ser un objeto de la mente ni del proceso de conceptualización; no se puede oír, ver, ni pensar, así que se lo alude con muchas imágenes tradicionales: la visión del ciego, un capullo floreciendo en el cielo. Cuando la mente conceptual procura aferrarlo, no encuentra nada, así que lo experimenta como vacuidad. Se lo puede conocer (y sólo se lo puede conocer) directamente. Se llama: naturaleza de Buda, no-mente, mente primordial, Bodhicitta Absoluto, mente de la sabiduría, mente del guerrero, Toda Bondad, Gran Perfección, aquello que no puede ser elaborado por la mente, Naturalidad.(Varela et al., 1992, p. 284)

Debe llamarnos la atención el hecho de que en la anterior descripción aparece la palabra "Absoluto", ante ella es ampliamente legítimo levantar la guardia y declarar: “[...] tanto lío con el fundamento, y al final, todo el asunto termina en otro fundamento". Compartimos dicha duda, de hecho, nos parece intrigante que los autores no se ocupen de ello. Sin embargo, si cabe sospechar que el absolutismo de dicho nivel enactuante opera como cierto tipo de fundamento, lo que aún se puede sostener es que de ser así, no sería un fundamento al estilo filosófico, debido a que es producto del desnivel, o en otras palabras, de otra instancia enactiva. En este sentido, los autores señalan:

Otra característica de la compasión espontánea, la compasión que no surge de la acción volitiva de patrones habituales, es que no sigue reglas. No deriva de un sistema ético axiomático, ni siquiera de exhortaciones morales pragmáticas. Reacciona ante las necesidades de la situación particular. (Varela et al., 1992, p. 285)

Por ende, amén de las dudas que pueda suscitar el planteo, debe reconocerse que señalan previamente que el constructo ético que retoman del budismo en ningún momento pretende ser una metafísica de la verdad (tanto en su lectura como en la misma gestación de la tradición), sino que lo convocan como descripción de la experiencia. Es decir, esta compasión espontánea sería el producto inmediato de la experiencia de enactuar desde el emergente mindfulness.

Así, como señalan los autores, para traer a presencia dicho estado, no hace falta inmiscuirse en ninguna tradición particular, sino que puede desarrollarse en el seno de toda cultura en tanto es una potencialidad que late en el amplio arco de las disponibilidades humanas, aunque lejos de ser algo dado perteneciente a la especie, debe (aunque no como mandato) ser alcanzado mediante algún conjunto de prácticas:

¿Cómo se puede alentar y corporizar en nuestra cultura esa actitud de interés abarcador, des-centrado, compasivo? Obviamente no se puede crear a partir de normas y exhortaciones racionalistas. Se debe desarrollar y corporizar a través de una disciplina que facilite el abandono de hábitos yoicos y permita que la compasión se vuelva espontánea y sostenida. (Varela et al., 1992, p. 287)

Una vez más, los autores ponen en el centro el hecho de que la crisis de fundamento no se puede enfrentar solo con estrategias racionales, es decir, recursos generados desde el emergente-enactuante yo pienso, sino que el camino supone trascenderlo. Como consecuencia, el centro deja de estar en la existencia de normas que regulen el comportamiento de los sujetos e impongan el reconocimiento de los otros y sus derechos como forma de evitar la tragedia del conflicto.

\section{El problema del fundamento en la perspectiva de Samaja}

En la postdata de 1994 a Epistemología y Metodología, el investigador argentino reflexiona sobre el problema de la caída o la 
inestabilidad del fundamento entendido como criterio de validez. Se refiere en este sentido a la suspensión de la objetividad que promulgan las críticas post-modernas debido a la denuncia de la expulsión de la dimensión subjetiva en tanto significación de lo propiamente humano. Samaja señala que la modernidad, bajo el influjo del liberalismo, obturó a la suma de dimensiones que conformaban la multidimensionalidad de la objetividad, y la limitó a lo mesurable, teniendo al dinero como máxima expresión. En ese sentido, senala que las críticas post-modernas no toman nota de dicha multidimensionalidad y a la vez, no suponen que haya algo que recuperar:

Como consecuencia de esto, la 'objetividad' es enfrentada absolutamente, sin matices, con la subjetividad, proponiendo una relación de incompatibilidad cuya superación es imposible.

Las posiciones extremas de la Post-modernidad parten de la oposición absoluta entre el Sujeto y el Objeto y del irreductible carácter subjetivo del proceso cognoscitivo. En consecuencia, cualquier intento de salvar al saber humano de la enajenación cuantitativista comporta el abandono de la objetividad como criterio del saber, y la universalidad y necesidad como rasgos de ese saber. (Samaja, 2004b, p. 366)

En esta dirección, el autor señala que uno de los principales problemas que acarrea dicha posición es que genera la carencia de elementos objetivos para juzgar como bueno o malo ciertos eventos de la historia humana, como genocidios, guerras mundiales, o la conquista de América. En cambio, en su perspectiva, los crímenes son objetivamente crímenes y los rechazos que éstos generan no son producto de sentimientos subjetivos, sino que son consecuencia del hecho de ser actos que violan el contrato social.

Por ende, propone sostener el estatuto de la objetividad a partir de un enfoque que incluya en ésta a los fenómenos intersubjeti- vos, postura que apoya en la lectura de Kant antes descripta:

La objetividad, como correlato de la subjetividad trascendental se convierte en intersubjetividad. Pero no en una "intersubjetividad" que podría resultar de un acuerdo ocasional, contingente, entre los sujetos, sino como la forma de la equilibración en que pueden coexistir los sujetos en una comunidad que "distribuye" entre ellos las cosas de "un único y mismo mundo". El sujeto trascendental es el sujeto que admite (o se constituye mediante) las formas básicas que están implicadas en las reglas de distribución. (Samaja, 2004b, p. 369)

De esta manera, Samaja postula que la filosofía kantiana permite armonizar a los enfoques objetivos con los hermenéuticos en el seno de un proyecto que denomina neo-dialéctico. En éste, la cuantización experimental es apoyada e integrada con miradas hermenéuticas leídas en clave de prejuicios legítimos, que actuarían, al igual que los fenómenos biológicos, en una lógica de unidad originaria (o equilibrio caído en la inmediatez)-desequilibración-nuevo equilibrio. A este respecto, cabe destacar que Samaja señala a Varela, junto a Hegel, Husserl, Sartre, Merleau Ponty y Gadamer; como autores que permiten e impulsan una síntesis entre el pensamiento objetivo y la hermenéutica. Compartimos dicha lectura, dado que en De Cuerpo Presente, los investigadores señalan que el enfoque enactivo tiene una pata biológica y otra cultural, por lo que los emergentes-enactuantes están condicionados por la cultura que habita el cuerpo que los pone en marcha. Sin embargo, el énfasis que Varela y sus colegas ponen en el proyecto de una ciencia sin apego al fundamento nos parece que marca una diferencia sustancial, dado que el desnivel que implica mindfulness, lleva a la construcción de un proyecto humano basado en otra intersubjetividad. Una que es producto de otro emergente-enactuante, no apoyada centralmente en la norma, aunque 
incluyéndola, sino en la trascendencia del egoísmo; no por la sujeción a un autocontrol de la clase que Samaja (2007) describe en "Las grandes estructuras argumentales posibles", en las que el enemigo externo cumple un rol central en la re-equilibración. Sin embargo, sí podemos destacar un acuerdo entre las perspectivas de los dos autores en el plano de la crítica a la noción de objetividad positivista. En la mirada del investigador argentino solo opera para totalidades cerradas:

[...] contrariamente, los seres vivos y los seres mentales se encuentran siempre en una situación de semicierre y semiapertura, y siempre están más allá de sí: allá en su medio, involucrados en sus objetos. (Samaja, 2004b, p. 372).

Esta noción de semi-cierre es central para comprender la apuesta de Varela y sus colegas a desarrollar técnicas de corporización que permitan tomar consciencia de los fenómenos de co-determinación. En este sentido, mindfulness sucede en la mente que ha trascendido el semi-cierre del yo pienso, por lo que, en consecuencia, genera un perfil enactivo en el que la información que ésta obtiene de su medio se ve modificada debido a que el individuo enactuante percibe en base a otro emergente, que aún se presenta como (otro) semi-cierre.

\section{Discusión}

En el presente trabajo procuramos comparar los planteos de Samaja y Varela, Thompson y Rosch (1992) con el objetivo de señalizar los caminos de reflexión diversos que presentan ambos enfoques amén de tener una base similar en la perspectiva autopoiética, en pos de remarcar la importancia de mindfulness como emergente que desafía a la epistemología moderna y que abre (y también reclama), en nuestra opinión, nuevos caminos para el proceso del conocer humano. Como hemos visto, ambas líneas de reflexión coinciden en la crítica al positivismo y al objetivismo que éste trae añadido al destacar una dimensión interna en los organismos vivos dotada cierta autonomía para variar las condiciones ambientales locales. Sin embargo, como hemos visto, a la hora de analizar la existencia humana, Samaja pone el acento en la importancia de la norma y de la intersubjetividad, mientras que los autores de De cuerpo presente resaltan la importancia enactiva del estado Mindfulness.

En este sentido, Samaja propone que cada estrato emergente en la secuencia epigenética elimina las determinaciones que generan las anteriores al paso que se instituye como fundamento y genera nuevas. En esta línea, el investigador argentino resalta la importancia de la aparición de la norma como herramienta para subjetivar a los individuos como medio para liberar a las sociedades de la eficacia biológica, entendida en la manera en que los clásicos de la modernidad la pensaron, es decir, como el amenazante estado de naturaleza en el que deseo incontrolado lleva a la lucha a muerte. En este contexto, para la perspectiva de Samaja, es central el primado del sujeto práctico, que encuentra en las filosofías de Kant y Vico, como experiencia del reconocimiento de los otros yoes.

En este ordenamiento teórico, bien podría plantearse que el estado mindfulness se corresponde con un posible nuevo salto en la secuencia epigenética. Sin embargo, según nuestra lectura, esa interpretación no es satisfactoria. Por empezar, en la perspectiva de Varela y sus colegas, el enfoque enactivo se propone para trascender el apego al fundamento. Podría decirse, que el carácter enactivo del nuevo estrato emergente posibilita esto, lo que induciría una modificación teórica en la lógica epigenética antes descripta. Sin embargo, nos parece que la perspectiva emergentista en la que se apoya la postura de Varela y sus colegas, no puede (o al menos no necesariamente) haber un ordenamiento 
secuencial del tipo de emergentes-enactivos que un cuerpo puede construir y convocar en tanto disponibilidad. De hecho, ahí se expresa la importancia de la crítica al concepto de representación en tanto búsqueda de superar todo marco teórico que trabaje con algún objeto dado. En este sentido, hay que destacar que la lógica epigenética que propone Samaja tiene inspiración en la psicología piagetiana, mientras que en opinión de los autores de Decuerpo presente, los planteos epigenéticos de Piaget tienen la debilidad de basarse en la lógica de la representación (Varela et al., 1992, p. 207). Por ende, en esta perspectiva, la importancia de la norma como herramienta de subjetivación puede ser corrida de su centralidad, y del lugar histórico-secuencial que cobra en la perspectiva de Samaja. Es decir, bien puede o pudo haber sociedades que hayan alcanzado el estado mindfulness antes de construir ordenamientos jurídicos claros y establecidos. Nos parece que no reconocer esto es pecar de cierto etnocentrismo involuntario. Inclusive, la re-lectura de la propia tradición occidental quizás podría poner esto en cuestión, aunque es algo que excede a este trabajo.

En esta dirección, según nuestra lectura, el modelo enactivo nos permite pensar en una clave multi-enactiva, es decir, reconocer la existencia de patrones de enacción que se dan una percepción diferente, no solo en grado, sino también en estructura. Esto no es nuevo para la perspectiva budista, ya que como vimos, en dicha tradición contemplan la existencia de dos tipos de conciencias, una que conoce a través de la relación sujeto/objeto y otra que no. La referencia al budismo no importa en términos doctrinales, sino como experiencia, en tanto opinamos que dicha posibilidad late en todos los cuerpos, aunque las diversas culturas la impulsen más o menos. La perspectiva occidental, impulsada por el yo pienso de Descartes claramente no privilegió el desarrollo de emergentes-enactuantes que operen por fuera de la relación sujeto/objeto, lo cual no significa que los cuerpos encarnados en todos estos siglos no hubieran podido desarrollar dicha disponibilidad. El resultado de esta inclinación, podemos aventurar, es el exceso de superyó y los procesos de normalización que tan bien describió Foucault; es decir, la desmesurada presencia de los otros en el individuo. Presencia que la experiencia budista no pretender borrar, tal como temen muchos intelectuales cuando se piensa en mindfulness como nueva herramienta neoliberal al servicio de la individualización, sino que resuelve en el aparente poderoso estado de compasión automática. Cabe destacar que las investigaciones en torno de las variaciones de activación del default mode network en función de la práctica de la meditación o del consumo de enteógenos han señalado sustanciales pruebas empíricas de la existencia de las dos distintas formas de consciencia que propone el budismo, o de los dos distintos tipos de emergentes-enactuantes desde una perspectiva científica (Andrews-Hanna et al., 2010; Brewer et al., 2011; Wen et al., 2013; Palhano-fontes, et al., 2015).

Por último, la toma de postura en torno a la existencia o no de diversos emergentes-enactuantes es solidaria del diferente énfasis que tiene la lectura de Kant en una y otra perspectiva. Mientras Samaja apuesta por salvar a la objetividad en el seno del proyecto neo-dialéctico y reivindica la importancia del sujeto práctico vinculado a sistemas normativos para comprender cabalmente a la filosofía de Kant, los autores de De cuerpo presente hacen hincapié en el recorte fenomenológico que deja fuera a lo noumenal de lo cognoscible y en el problema de fundar el conocimiento en una consciencia trascendental inaccesible para la experiencia. Dada la evidencia empírica recién citada que apoya la idea de la existencia de múltiples sistemas enactivos, nos parece necesario expandir los enfoques teóricos sobre la subjetividad a miradas que puedan analizar la posibilidad de que lo noumenal tenga eficacia sobre 
aquello que la modernidad designó como capaz de ser estudiado. Si bien, los estudios citados fueron construidos a partir de lógicas de investigación objetivas encuadrables en la perspectiva del sujeto trascendental, las consecuencias respecto de la experiencia del sentido parecen evadirlo. De todos modos, esto no significa que haya que desbaratar la importancia y la eficacia de la intersubjetividad y sus normas. Planteamos simplemente que están dadas las condiciones epistémicas para re-localizar su importancia en el seno de un proyecto multi-enactivo que incluya emergentes-enactivos que se dan percepciones de una naturaleza que hasta el momento la tradición occidental señalo como noumenales.

\section{Bibliografía}

- Andrews-Hanna, J., Reidler, J., Huang, C. y Buckner, R. (2010). "Evidence for the default network's role in spontaneous cognition". Journal of neurophysiology, 104(1), pp. 322-335.

- Brewer, J., Worhunsky, P., Gray, J. Tang, Y., Weber, J. y Kober, H. (2011). "Meditation experience is associated with differences in default mode network activity and connectivity". Proceedings of the National Academy of Sciences, 108(50), pp. 20254-20259.

-Maturana, H. y Varela, F. (1986). El árbol del conocimiento. Chile: Ed. Universitaria.

- Palhano-Fontes, F., Andrade, K., Tofoli, L., Santos, A., Crippa, J., Hallak, J. y De Araujo, D. (2015). "The psychedelic state induced by ayahuasca modulates the activity and connectivity of the default mode network". PloS one, 1O(2), e0118143.

- Samaja, J. (2004). Epistemología de la salud: reproducción social, subjetividady transdisciplina. Buenos Aires: Ed. Lugar.

— Samaja, J. (2004b). Epistemología y metodologia: Elementos para una teoría de la investigación cientifica. Buenos Aires: Editorial Universitaria de Buenos Aires, 3era edición.
— Samaja, J. (2007). “Las grandes estructuras argumentales posibles". Perspectivas Metodológicas, [7(1)]. Publicación de la Maestría en Metodología de la investigación científica. Buenos aires: Facultad Nacional de Lanús.

—Ynoub, R. (2016). “'¿Y dónde está el sujeto?': indicadores enunciativos y desafíos metodológicos para la investigación de la subjetividad". En Ambrosini, C., Mombrú, A., Méndez, P., (comp). Remedios de Escalada, EDUNLa.

- Varela, F., Thompson, E. y Rosch, E. (1992). De cuerpo presente, Las ciencias cognitivas y la experiencia humana. Barcelona: Gedisa.

- Wen, X., Liu, Y., Yao, L. y Ding, M. (2013). “Top-down regulation of default mode activity in spatial visual attention". Journal ofNeuroscience, 33(15), pp. 6444-6453. 